\section{Clouds (Cirrus, High Clouds).}

390. A Gentle Breeze. Hon. Duff Tollemache. Form and colour of the cirrus cloud very natural.

505. Fifteen-metre Vachts Rounding the East Lepe Buoy: Cowes Regatta. Alice Fanner. The cirrus cloud in this seascape is very good. The small cumuli and wisps of cirrus very natural.

689. Six-metre Yachts Racing at the International Regatta, Solent, I9II. Alice Fanner. The cirrus clouds are well represented.

\section{Sunsets, Sunrises (Sky).}

13. Scur-na-Gillian, Sligachan. Finlay Mackinnon. A beautiful picture with a bold effect of sunset. Is not the near side of the right-hand peak too much illuminated?

55. Evening on the Sands of Towyn. B. W. Leader, R.A. A fine sunset sky; shape and colour of clouds very true. Reflection in water and breaking wave very effective. A fine picture.

147. "The Day was Sloping towards his Western Bower." Joseph Farquharson, A. Have we not here a too great diversity of colours? Should not the yellow tinge be more universal and be more represented on the hill on the left (which seems too pink) and also on the under portions of the clouds?

205. Evening's Last Gleam. B. W. Leader, R.A. $A$ fine study and lighting excellent. The sunlight on the upper portion of the clouds very effective.

429. The Matterhorn, from the Triftkummen: Sunrise. Edward T. Compton. The colours here are very true in tone, and the wisps of mists on the mountains appear already to be in the process of being dissipated.

465. The Prize. Donald Maxwell. A bold picture. Very striking sunset effect, both in the sky and by refiection. Excellent colouring.

669. A Peaceful Valley. Hon. Walter James. This sunset scene is accurately painted, and the cloud forms, colouring, and general gradation of the tones very true. The atmospheric absorption in the distant landscape naturally indicated.

790. Into the West. Robert W. Allen. The sequence of the colouring at the different altitudes very natural. The type of cloud represented is true, but there is not sufficient of the sunset colours reflected in the water.

\section{Sun's Disc.}

29. The Wane of an Autumn Day. J. Coutts Michie. The disc of the sun is very much too large, and, judging by the angles subtended by the objects in the foreground, it is more than twice the size it should be.

\section{Moon.}

353. Moonrise: the Dunes, Pas-de-Calais, France. $H$. Hughes-Stanton. The full moon much too large, judging by the trees in the foreground.

369. Moonlight on the Cornish Riviera. R. Borlase Smart. Moon too large for similar reasons; also sky around the moon too blue.

782. Moonrise over the Marsh. Stuart Lloyd. The moon here is more natural, but still a little too big judging by the trees in the foreground.

122. Evening. William Brock. In this picture only a small portion of the upper part of the moon is seen above the horizon. By its horizontal extent and curvature it is very much too large, and calculations suggest that if the whole disc were visible it would be three or four times too large.

123. Truilight. Fred Hall. The size and colour of the moon are good. The woman and cattle in foreground are perhaps too much illuminated.

I51. An Autumn Evening in the Alps.

NO. 22 I9, VOL. 89]
Stokes, A. The sun is here supposed to be below the horizon on the right, consequently the visible illuminated portion of the moon ought to be leaning slightly over to the right also, and not as shown. The clouds are also too bright relative to the moon.

\section{Rainbow.}

468. The Home Port. W. Ayerst Ingram. This would be a fine picture if the rainbow were omitted. The sun is setting on the right of the picture more than $90^{\circ}$ away from the observer. This can be gathered from the position and sunlight on the ship in the centre of the picture and other illuminated objects. As one of the fundamental conditions for seeing a rainbow is that the sun should be at the back of the observer, it is not possible for a rainbow to be included in the picture under the existing sunset position.

\section{ReFLECTIONS.}

i67. A Little Mishap. Sir E. J. Poynter, Bart., P.R.A. An excellent study of reflections.

William J. S. Lockyer.

\section{INTERNATIONAL ASSOCIATION OF CHEMICAL SOCIETIES.}

THE International Association of Chemical Societies held its first formal meeting in Paris in April, rgrr, when the delegates nominated by the French, German, and English Chemical Societies met and ratified the statutes of the association, the council of which as at first constituted consisted of Profs. Béhal, Hanriot, and Haller representing the Société Chimique de France, Profs. Jacobson, Ostwald, and Wichelhaus representing the Deutsche chemische Gesellschaft, and Profs. Frankland, Meldola, and Sir Wm. Ramsay representing our Chemical Society. The second conference was held in Berlin last month, under the presidency of Prof. Ostwald and the vice-presidency of Prof. Wichelhaus, when the council was further enlarged by the addition of Profs. Carrara, Oglialoro, and Paternò representing the Italian Chemical Society, Profs. Kurnakow, Tschugaeff, and Walden representing the Russian Chemical Society, Dr. Day and Profs. Noyes and Richards representing the American Chemical Society, and Profs. Fichter, Guye, and Werner representing the Swiss Chemical Society. Certain other societies representative of Holland, Denmark, Austria, and Norway were also affiliated, but were not directly represented on the council. Prof. Meldola, having been unable to attend the meeting, withdrew from the representation of the Chemical Society, and was replaced by Prof. Crossley.

The first work of the Association is the consideration of the nomenclature of inorganic and organic chemistry and the unification of the notation of physical constants. In connection with the latter part of the programme, the committee has been strengthened by the addition of M. Marie, of the French Society of Physical Chemistry. The English committees appointed to report upon these preliminary branches of work are, for inorganic nomenclature, Sir Wm. Ramsay, Dr. J. C. Cain, and Dr. Harden; for organic nomenclature, Profs. Kipping and Wynne and Dr. 
Cain; and for physical constants, Drs. Wilsmore and Cain and Prof. Findlay. Dr. Cain's services have been secured for all three committees in view of his editorship of the publications of the Chemical Society. The other chemical societies have also appointed influential committees to deal with these same subjects, and the reports of these committees were considered at the Berlin congress last month. At this gathering thirteen societies having a total membership of 18 , 000 were represented. The next meeting of the Association is to be held in London in September, I9I3, under the presidency of Sir Wm. Ramsay, when, in addition to the subjects already being dealt with, the question of the possibility of arriving at an international understanding with respect to editing and to the publication of abstracts will be considered.

In view of the overlap and duplication of publication now being carried on by several societies all doing the same kind of work, it will be seen that great need exists in the interests of chemical literature for making a serious effort towards centralisation. This can only be done by international co-operation, and it is to be hoped that some practical scheme may be developed as one result of the useful and valuable labours which the new Association has entered upon.

\section{MR. JOHN GRAY.}

$\mathrm{W}^{\mathrm{b}}$ $\mathrm{E}$ announced with regret last week the death of Mr. John Gray, one of the examiners of the Patent Office, and well known for enthusiastic and painstaking efforts on behalf of anthropology. Mr. Gray was born at Strichen, Aberdeenshire, on January 9, 1854. He was educated at the Aberdeen Grammar School and at Edinburgh University, where he took the second prize in Prof. Fleeming Jenkin's class in 1873 . He obtained the first Royal Exhibition at the Royal School of Mines, London, in 1875 , and later received the associateship in metallurgy. $\mathrm{He}$ took his degree in Edinburgh in 1878 , and entered the Patent Office in that year.

Mr. Gray made a study of many electrical problems, especially those bearing on electrical influence machines. He published a book on this subject, in which he traced the historical development of influence machines, and described such modern forms as those of Kelvin, Voss, Holtz, and Wimshurst. He was well known for his connection with physical anthropology, and took an active part in all recent efforts to secure its recognition by the State. He was elected treasurer of the Royal Anthropological Institute in 1904, and his efforts to improve the financial condition of that body were crowned with complete success. In 1904 he gave evidence before the Interdepartmental Committee on physical deterioration, and, in conjunction with the late Prof. Cunningham, submitted a scheme for a national anthropometric survey.

At the request of the Royal Anthropological Institute, Mr. Gray organised a deputation to meet the late Sir Henry Campbell-Bannerman, the object of which was to impress on the Government the necessity of carrying out the recommendation of the Physical Deterioration Committee with regard to a national survey. $\mathrm{He}$ designed a number of novel anthropometric instruments, some of which are extensively used by anthropologists, and for which he received a diploma of honour at the Franco-British Exhibition.

Mr. Gray took a deep interest in his native county, and, in conjunction with Mr. J. F. Tocher, conducted a series of anthropometric measurements on the population of Aberdeenshire from 1895 to 1899 , the results of which were published in the Journal of the Royal Anthropological Institute, and in the Transactions of the Buchan Club, of which he was president in 1899. In 190I-1902, along with Mr. Tocher, he advocated a survey of the colour characters of school children of Scotland, and joined the Scottish committee on its formation, the other members being Sir William Turner, K.C.B., F.R.S., Prof. R. W. Reid, and Mr. Tocher. Both he and Mr. Tocher published memoirs bearing on the results of the survey from different viewpoints. Mr. Gray's memoir appeared in the Journal of the Royal Anthropological Institute (Vol. 37, 1907). In this memoir Mr. Gray gave his views on the distribution of colour in Scotland, and displayed local groupings by a system of contour lines in a series of maps.

Mr. Gray's many contributions to anthropological literature include the following:"Measurements on Papuan Skulls" (J.R.A.I., Igor), "Indian Coronation Contingent" (B.A. Report, 1902), "England before the English" (B.A. Report, 1906), "A New Instrument for Determining the Colour of the Hair, Eyes and Skin" (Man, 1908), and "Who Built the British Stone Circles?" (NATure, December 24, I908). Mr. Gray is survived by a widow and one daughter.

\section{NOTES}

THE French Ambassador took the chair on May 3 at the first of the series of four lectures being delivered by M. Henri Poincaré on mathematical subjects at the University of London: the two remaining lectures will be given on May ro and Ir. M. Poincaré, who was born in 1854 , was educated at the lycée at Nancy, entered the École Polytechnique, being placed first on the list, and on leaving it became a Government mining engineer (ingénieur des mines), this employment being reserved for those who occupy very high places at the examen de sortie of the school. He exercised this profession only for a short time; in 188I he was appointed to a lectureship in pure mathematics at the Sorbonne, and when M. Lippmann exchanged the chair of mathematical physics for a chair of experimental physics, M. Poincaré succeeded him. Later, on the death of M. Tisserand, M. Poincare succeeded to the chair of mathematical astronomy. He has made contributions of the greatest importance to pure and applied mathematics, astronomy, and mathematical phvsics, and also to scientific- 